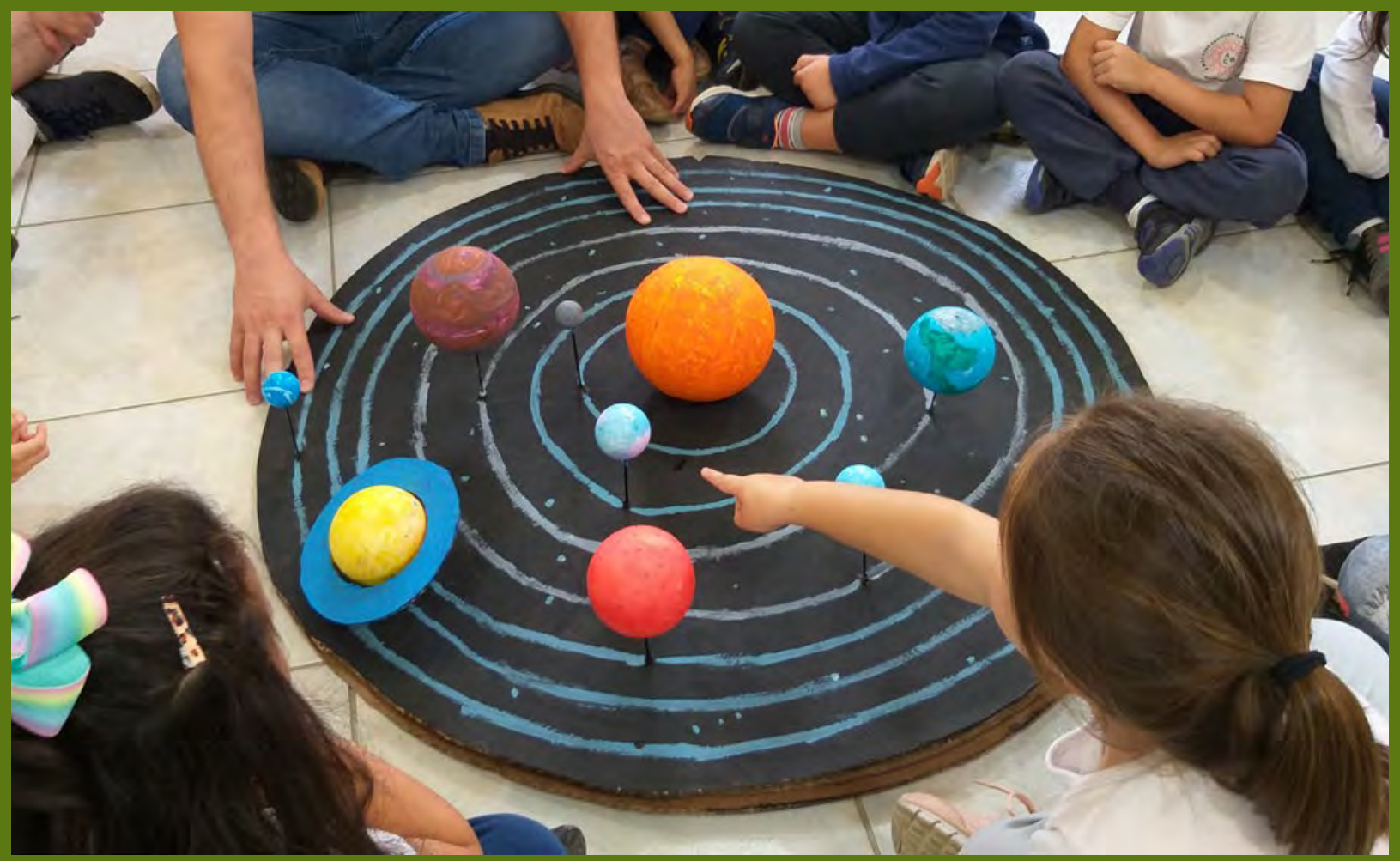

\title{
Educação científica para crianças por meio da contação de histórias: relato de uma experiência na Educação Infantili
}

\author{
Anderson Bertoldi - anderson.bertoldi@ifsc.edu.br 2 \\ lara Maitê Campestrini Binder - iara.campestrini@ifsc.edu.br ${ }^{3}$
}

\section{RESUMO}

Especialistas em educação científica apontam um crescente desinteresse dos jovens pela ciência. Os resultados do PISA 2018 mostram o Brasil na última posição da América do Sul, juntamente com a Argentina, em letramento científico. Neste relato de experiência, apresenta-se um projeto de extensão que teve como objetivo estimular, por meio de atividades lúdicas, a reflexão científica em crianças da Educação Infantil de uma rede municipal de ensino da Região Norte de Santa Catarina. Como resultados deste projeto, identificouse o interesse dos alunos pelas atividades de extensão, além da possibilidade de curricularização da extensão.

PALAVRAS-CHAVE: educação científica; educação infantil; contação de histórias; curricularização da extensão.

1 Projeto de extensão executado com recursos do Edital 2019 PROEX 09 - Curta Duração.

2 Doutor em Linguística Aplicada pela Universidade do Vale do Rio dos Sinos. Professor de Português do Instituto Federal de Santa Catarina - Câmpus Jaraguá do Sul - Rau.

3 Mestre em Física pela Universidade do Estado de Santa Catarina. Professora de Física do Instituto Federal de Santa Catarina - Câmpus Jaraguá do Sul - Rau. 


\title{
Scientific education for children through storytelling: reporting an experience in Early Childhood Education
}

\author{
ABSTRACT
}

Experts in scientific education point to a growing lack of interest in science among young people. The results of PISA 2018 show Brazil in the last position in scientific literacy in South America, alongside Argentina. This experience report presents an extension project that aimed to stimulate children in Early Childhood Education to scientific reflection, through ludic activities, in municipal schools of a municipality in the Northern Region of Santa Catarina.

KEYWORDS: scientific education; early childhood education; storytelling; curricular extension.

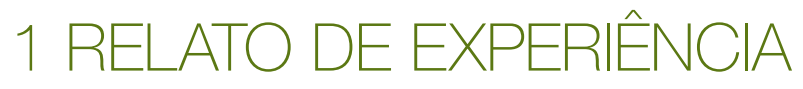

Especialistas em educação científica, como Pozo e Crespo (2009), apontam um crescente desinteresse pela ciência que lhes é ensinada. Os resultados do PISA 2018 (PISA, 2019) mostram o Brasil na última posição da América do Sul, juntamente com a Argentina, em letramento científico. Considerando esses apontamentos, o Grupo de Pesquisa Letramento, Ciência e Tecnologia tem proposto diferentes ações de ensino, pesquisa e extensão, tanto em formação continuada de professores quanto em ações de extensão com alunos da Educação Infantil. Neste relato de experiência, descreve-se uma dessas atividades, desenvolvida como projeto de extensão com alunos da Educação Infantil de uma rede municipal de ensino da Região Norte de Santa Catarina. Tradicionalmente, no contexto da rede de ensino em que foi realizado o projeto, o ensino de ciências como uma estratégia pedagógica na Educação Infantil é pouco utilizado, por acreditar-se que a criança não teria capacidade para se envolver em discussões científicas. No entanto, um relatório feito pelo National Research Council (2007) defende que não há fundamentação científica para essa crença. Recentemente, a Base Nacional Comum Curricular (BRASIL, 2019) estabelece a exploração da ciência e da tecnologia como um dos direitos de aprendizagem e desenvolvimento na Educação Infantil.

0 projeto Contação de Histórias Científicas na Escola foi uma ação de extensão desenvolvida em associação com a Unidade Curricular de Comunicação e Expressão, no Curso de Engenharia Elétrica do Câmpus Jaraguá do Sul - Rau do Instituto Federal de Santa Catarina (IFSC), no segundo semestre de 2019. A ação, que integrou 33 estudantes da referida Unidade Curricular, foi organizada em quatro fases: (i) ambientação dos alunos e organização da turma em grupos; (ii) realização de oficinas de escrita e contação de histórias científicas; (iii) realização de sessões de contação das histórias científicas desenvolvidas pelos alunos para crianças de 4 a 6 anos, de escolas de Educação Infantil de um município da Região Norte de Santa Catarina; e (iv) avaliação da ação e autoavaliação dos alunos. As ações desenvolvidas pelos alunos do curso de Engenharia atingiram aproximadamente 240 pessoas, entre alunos e professores da Educação Infantil.

0 projeto teve início com a ambientação dos alunos ao projeto (Figura 1). Nessa oportunidade, os alunos realizaram uma roda de conversa e compartilharam com os colegas uma história de infância. Para motivá-los a rememorar suas experiências e sua curiosidade infantis, a sala foi decorada com brinquedos e doces. Os alunos, nesse dia, foram recebidos na sala de aula com músicas infantis e tiveram de tirar seus sapatos e se sentar no chão para participar da roda. A atividade buscava despertar a criatividade dos alunos extensionistas e fazê-los lembrarem da curiosidade típica da infância. Encerrando a atividade de ambientação, apresentou-se aos alunos a proposta do projeto de extensão: que eles criassem histórias, baseadas em fatos científicos ou fenômenos naturais, para serem contadas a crianças da Educação Infantil. Junto à contação da história, uma atividade de experimentação científica deveria ser planejada, visando trazer para o concreto os conceitos científicos. Os alunos puderam, então, organizarem-se livremente em grupos para desenvolverem suas propostas de histórias e experimentos. 


\section{Figura 1 - Ambientação dos Alunos ao Projeto}

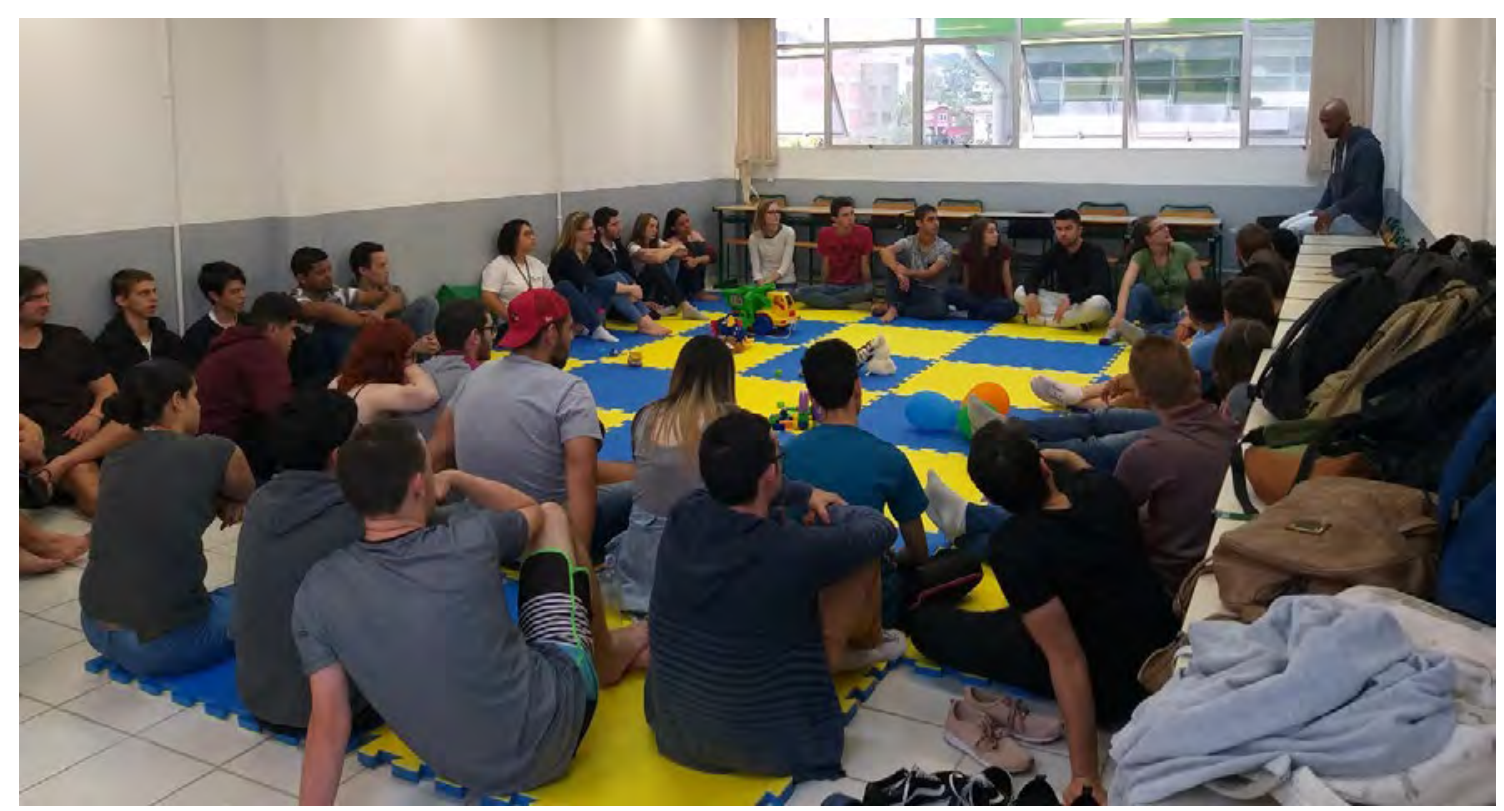

FONTE: Dados do projeto.

A segunda etapa do projeto foi o desenvolvimento de oficinas de escrita de contos (Figura 2) e de contação de histórias (Figura 3), além do oferecimento de horários de atendimento para orientação quanto às questões científicas envolvidas em suas propostas de contação de história. Cada grupo teve de criar uma história original que envolvesse algum fato científico ou fenômeno natural, e que pudesse ser vivenciada pelas crianças participantes da contação na forma de um experimento ou brincadeira. As histórias, então, foram analisadas pelo professor da Unidade Curricular de Comunicação e Expressão e por um professor de Física da Instituição, que sugeriram melhorias nos aspectos narrativos e científicos dos contos.

\section{Figura 2 - Oficina de Escrita de Contos Científicos}

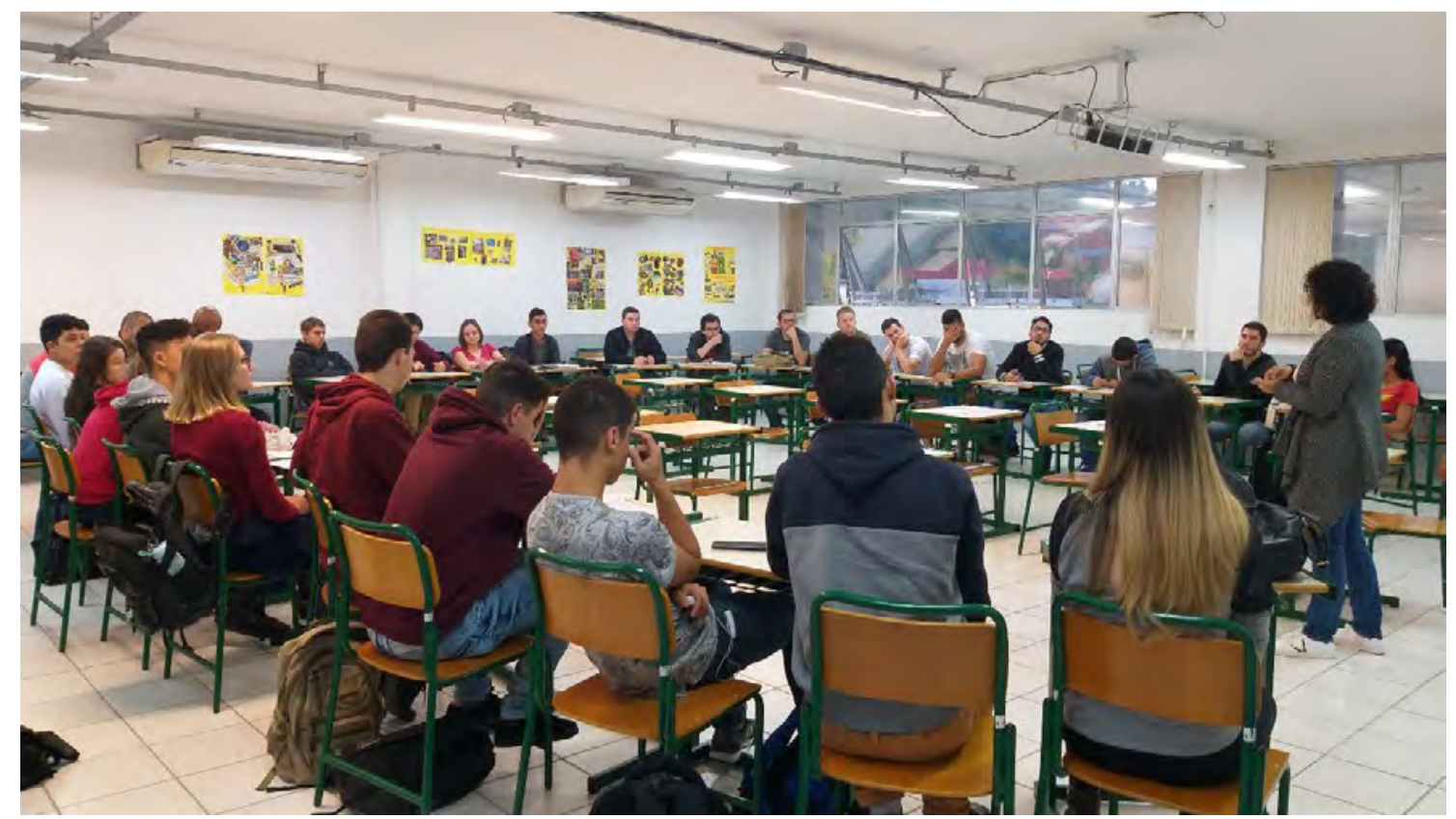

FONTE: Dados do projeto.

Depois da reescrita dos contos, os grupos praticaram a contação das histórias. Para tanto, foi realizada uma oficina de contação de histórias com a contadora Felícia Fleck. Buscando a integração entre 
o grupo de alunos extensionistas e as professoras que os receberiam em suas salas de aula, participaram dessa oficina tanto alunos extensionistas quanto professoras da Educação Infantil.

\section{Figura 3 - Oficina de Contação de Histórias}

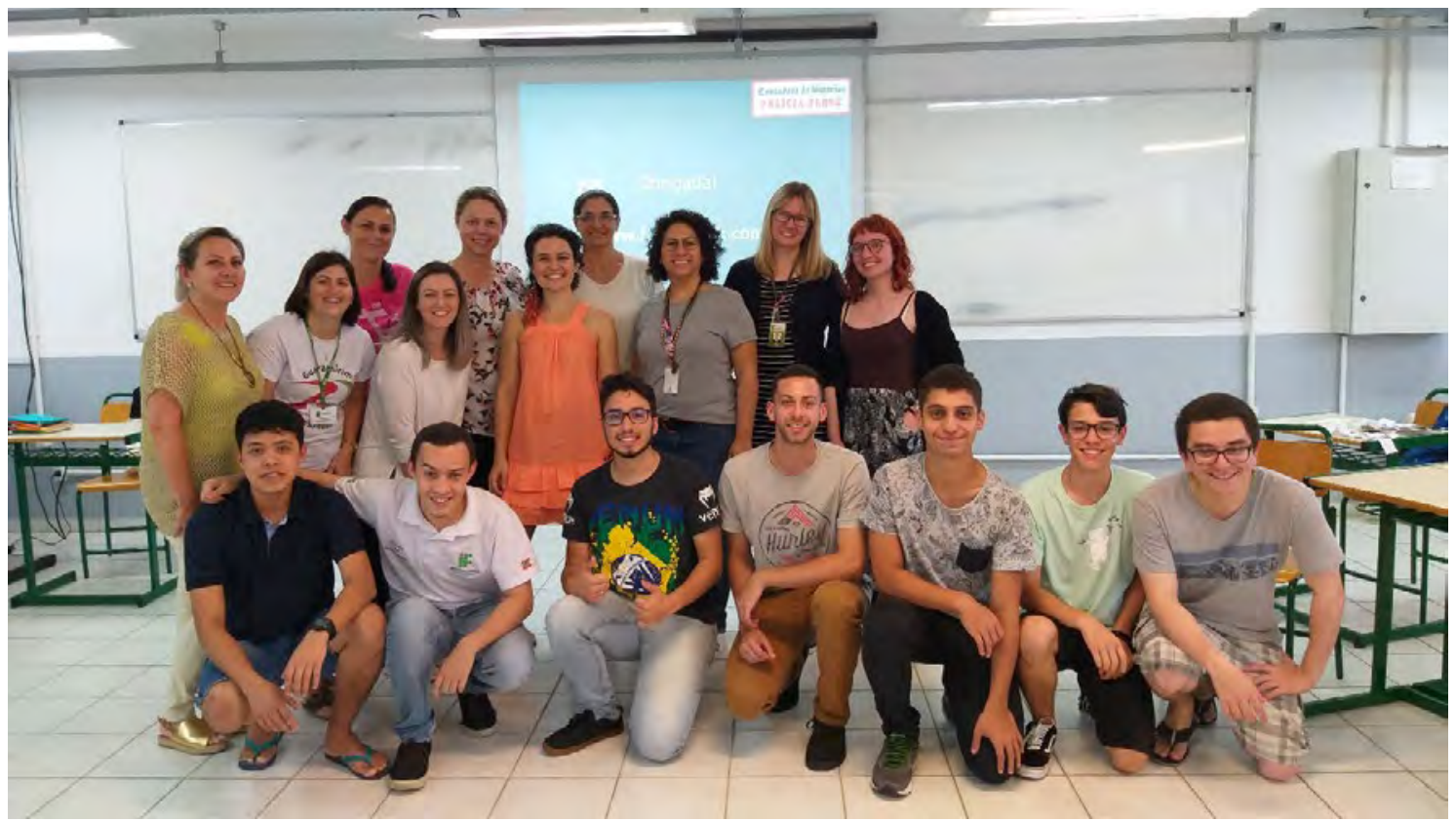

FONTE: Dados do projeto.

Por fim, as contações de histórias científicas foram realizadas em dois momentos distintos. Uma primeira sessão foi realizada na biblioteca do Câmpus Jaraguá do Sul - Rau, durante a Semana Nacional do Livro e da Biblioteca (Figura 4). Nesse dia, quatro turmas de educação Infantil visitaram a biblioteca e assistiram às contações de histórias e às exibições de maquete e experimentos realizadas pelos extensionistas.

Figura 4 - Contação Realizada na Biblioteca do Câmpus Jaraguá do Sul - Rau

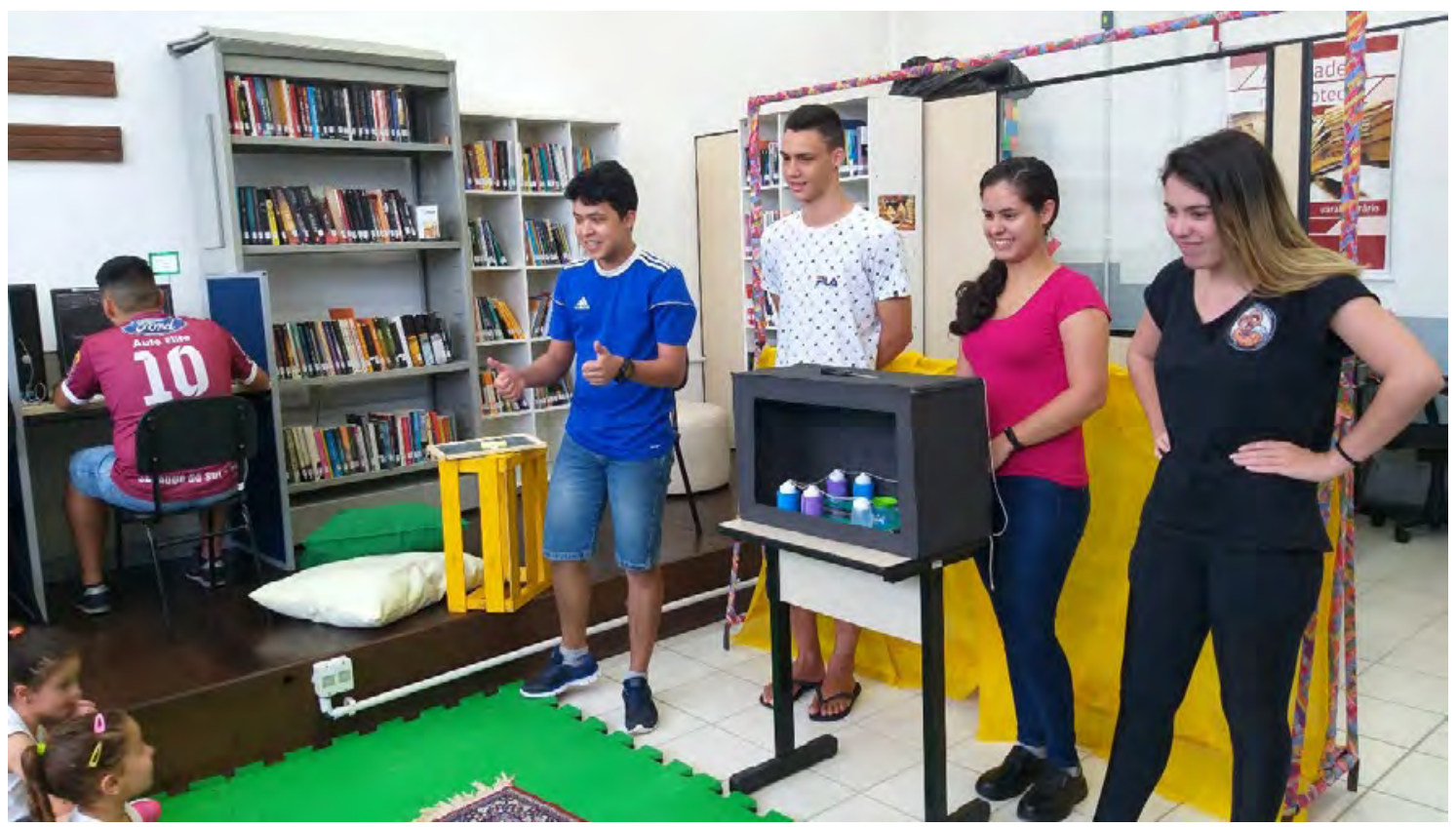

FONTE: Dados do projeto. 
Uma segunda sessão foi realizada em escolas de Educação Infantil de uma rede de ensino municipal da Região Norte de Santa Catarina. As participações foram realizadas em sete turmas de Educação Infantil, por seis grupos de alunos, que contaram suas histórias e ilustraram suas contações com maquetes, experimentos e jogos. As temáticas exploradas por esses grupos incluíram desde a distribuição de energia elétrica e os riscos de choques elétricos até os movimentos de rotação e translação do planeta Terra e seus efeitos de dia e noite e de mudanças de estações (Figura 5).

Figura 5 - Contação Realizada em Escola

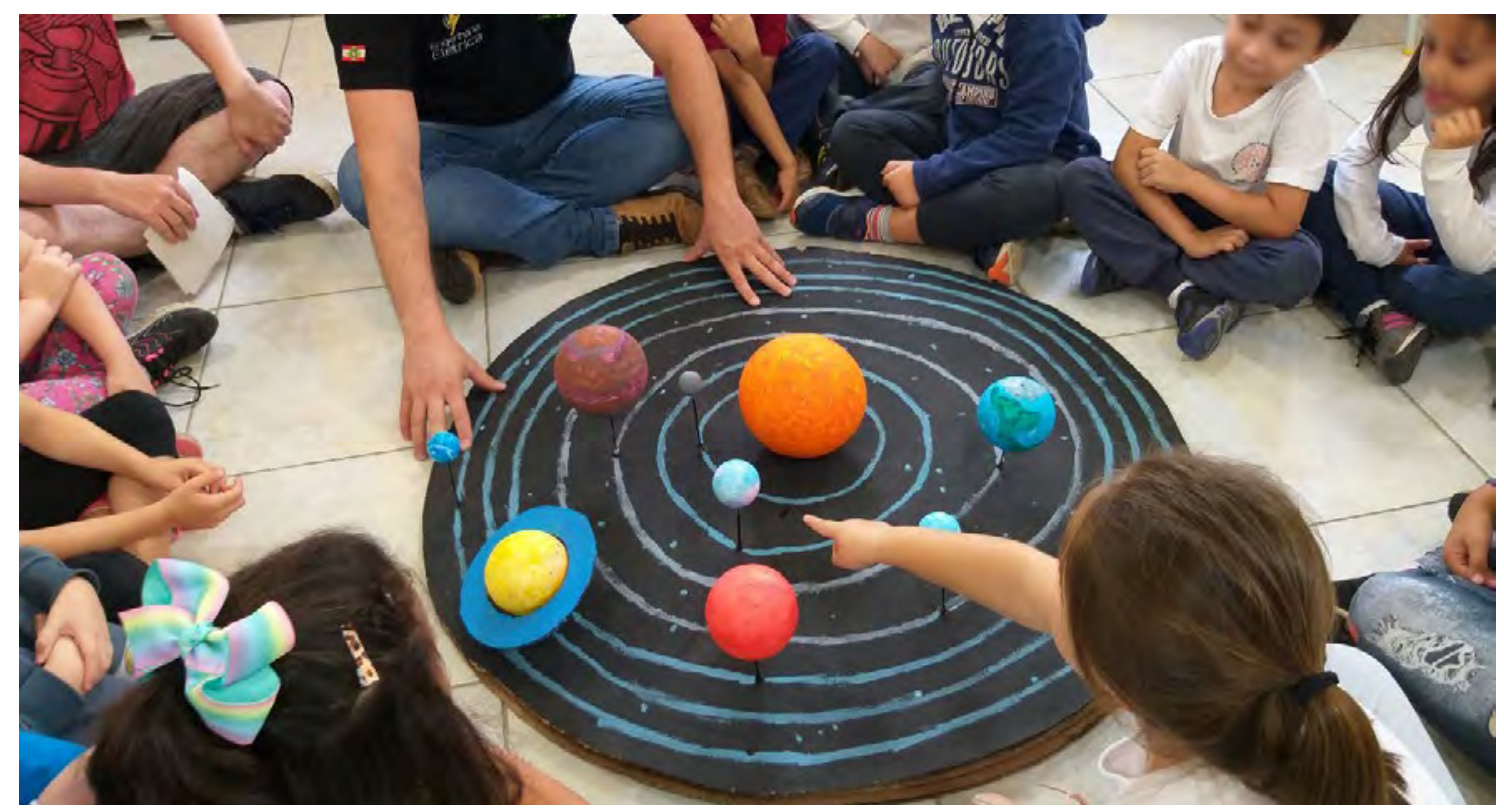

FONTE: Dados do projeto.

Ao fim das contações de histórias, os alunos foram avaliados pelas professoras que os receberam em suas salas de aula e, ao voltarem à aula de Comunicação e Expressão, pediu-se a eles que fizessem suas autoavaliações. A partir dessas avaliações, pode-se depreender alguns resultados do projeto. Quanto aos alunos extensionistas, eles avaliaram a ação como importante para o seu desenvolvimento como cidadãos e para a sua preparação profissional, auxiliando-os em sua comunicação com públicos diversos depois de formados. Identificou-se nos alunos um grande interesse em desenvolverem a atividade de extensão, com a mobilização de todos para ensaiar as contações, montar os experimentos e maquetes e deslocarem-se até as escolas onde fariam as contações. As atividades de extensão foram integradas à Unidade Curricular de Comunicação e Expressão, uma vez que a comunicação oral e a apresentação faziam parte dos conteúdos a serem trabalhados com esses alunos. No entanto, trabalhar esses conteúdos na forma de projeto de extensão permitiu aos alunos ressignificar a sua importância na formação profissional. Não se tratava apenas de mais um conteúdo, mas de uma situação real de comunicação.

Quanto às crianças, o diálogo com estudantes mais velhos permitiu-lhes estabelecer relações entre os conteúdos trabalhados nas contações de histórias com suas vidas diárias, como o fato de já terem levado um choque ou de os pais não lhes permitirem manusear equipamentos elétricos. As professoras que receberam os extensionistas também elogiaram a iniciativa, já que os extensionistas conseguiram cativar a atenção e o interesse dos pequenos. Dessa forma, abriu-se uma oportunidade de diálogo com a comunidade do entorno do câmpus, favorecendo não só a educação científica dessas crianças, mas o fortalecimento da Instituição perante essa comunidade.

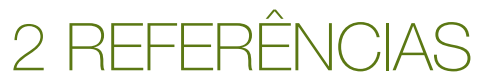

BRASIL. Ministério da Educação e do Desporto. Secretaria de Educação Básica. Base nacional comum curricular. Brasília: MEC/SEB, 2019.

NATIONAL RESEARCH COUNCIL. Committee on Science Learning, Kindergarten Through Eighth Grade. Taking

science to school: learning and teaching science in grades K-8. Washington: National Academy of Sciences, 2007. 
PISA: Programme for International Student Assessment. In: ORGANISATION for Economic Co-operation and Development (OECD). [S.I.], 2019. Disponível em: https://www.oecd.org/pisa/. Acesso em: 13 fev. 2020.

POZO, Juan Ignacio; CRESPO, Miguel Ángel Gómez. A aprendizagem e o ensino de ciências. Do conhecimento cotidiano ao conhecimento científico. 5. ed. Porto Alegre: Artmed, 2009. 